\title{
Temozolomide-Induced Shrinkage of a Pituitary Carcinoma Causing Cushing's Disease - Report of a Case and Literature Review
}

\author{
Lorenzo Curtò $^{1, *}$, Maria L. Torre ${ }^{1}$, Francesco Ferraù ${ }^{1}$, Vincenzo Pitini ${ }^{2}$, \\ Giuseppe Altavilla², Francesca Granata ${ }^{3}$, Marcello Longo ${ }^{3}$, Leo J. Hofland ${ }^{4}$, \\ Francesco Trimarchi ${ }^{1}$, and Salvatore Cannavò ${ }^{1}$ \\ ${ }^{1}$ Department of Medicine and Pharmacology - Section of Endocrinology, ${ }^{2}$ Department of \\ Medical Oncology, and ${ }^{3}$ Department of Radiological Sciences, University of Messina, \\ Italy; ${ }^{4}$ Department of Internal Medicine, Division of Endocrinology, Erasmus Medical \\ Center, Rotterdam, The Netherlands \\ E-mail: curto.loren@libero.it
}

Received September 10, 2010; Revised October 19, 2010; Accepted October 20, 2010; Published November 4, 2010

Temozolomide (TMZ) is an alkylating chemotherapeutic agent that has recently been used in some cases as a new therapeutic tool for pituitary carcinomas and aggressive pituitary adenomas. In this report, we present the case of effective TMZ treatment in a 42 year-old man with ACTH-secreting carcinoma. The tumor grew progressively over 4 years, from 2.2 to $31.1 \mathrm{~cm}^{3}$, despite three surgical approaches and $\mathrm{Y}$-knife treatment. Ki67 increased from 2 to $18 \%$. An intradural metastasis at the foramen magnum was detected by MRI after the third operation. Thereafter, four cycles of 5-day TMZ administration $\left(200 \mathrm{mg} / \mathrm{m}^{2} /\right.$ day during the first, and $150 \mathrm{mg} / \mathrm{m}^{2} /$ day during the following cycles) induced dramatic tumor size reduction ( $>90 \%)$. Clinical conditions improved progressively and, after 17 months from the beginning of TMZ administration, the patient is still alive. The treatment was well tolerated except for a transient thrombocytopenia (grade 4 WHO).

KEYWORDS: temozolomide, pituitary carcinoma, chemotherapy, $\mathrm{O}^{6}$-methylguanine DNA methyltransferase, Cushing's disease

\section{INTRODUCTION}

Pituitary carcinomas are extremely rare, representing no more than $0.1-0.2 \%$ of all pituitary tumors[1,2,3]. Most of them are diagnosed as prolactin (PRL)- or adrenocorticotropin (ACTH)-secreting invasive macroadenomas, but show aggressive growth characteristics and a propensity to metastasize with time[2,4,5,6]. Some reports suggested that silent ACTH-secreting macroadenomas, which cause signs or symptoms due to mass effect rather than Cushing's disease, are at increased risk of malignant transformation[7]. Corticotroph carcinomas, including those that are not active, account for $40 \%$ of all pituitary carcinomas[2,4,8]. The mechanisms underlying transformation of adenomas into carcinomas are 
not fully understood, and reliable predictive markers for transformation have not been identified to date $[9,10]$. Prognosis is poor in most cases, as surgery, radiotherapy, or drugs currently employed in the treatment of pituitary adenomas are not effective in controlling tumor growth and occurrence of metastases. Temozolomide (TMZ), an alkylating cytostatic drug introduced for treatment of glioblastoma multiforme, but effective in other CNS neoplasms as well as in neuroendocrine tumors, has also recently been proposed for management of pituitary carcinomas and aggressive pituitary adenomas $[11,12,13,14]$. This drug can alkylate and methylate specific guanine residues, damaging DNA and triggering the death of tumor cells. Effectiveness of TMZ is related to the down-expression of O-6-methylguanine-DNA methyltransferase (MGMT), an enzyme able to repair this type of DNA damage[12,15].

To date, only 15 cases of pituitary carcinomas treated with TMZ have been reported. We present the thirteenth case of effective TMZ treatment in patients with pituitary carcinoma, the fifth concerning a patient with ACTH-secreting malignant tumor. In our patient, TMZ induced a dramatic shrinkage of the tumor with stabilization of the intradural metastasis, after four cycles of treatment only, and dramatic improvement in clinical condition.

\section{CASE REPORT}

A 42-year-old man was referred to our outpatient clinic in November 2004 with dramatic signs and symptoms of hypercortisolism, including diabetes mellitus, and widespread osteoporosis causing recurrent spontaneous rib fractures over 5 years. Physical examination showed abdominal obesity (BMI $32 \mathrm{~kg} / \mathrm{m}^{2}$ ), skin hyperpigmentation, edema of the lower limbs, livid striae on the abdomen, and severe hypertension. Endocrine investigation is summarized in Table 1. MRI showed an invasive pituitary mass extending to the suprasellar region with expansion into the left cavernous sinus $\left(2.2 \mathrm{~cm}^{3}\right)$. After a transsphenoidal microscopic approach, which allows a subtotal resection of the tumor, histology revealed a sparsely granulated, PAS-negative, chromophobe adenoma, characterized by solid/diffuse architecture and rare mitotic figures. No Crooke's hyaline change was evident. Immunohistochemistry was positive for ACTH in $70 \%$ of cells and tumor proliferation activity, calculated by the percentage of cells expressing Ki-67 antigen, was 2\%. Immunohistochemical staining for the Ki-67 antigen was performed using the MIB-1 antibody and the avidin-biotin complex method using paraffin-embedded blocks cut into 3- to 4- $\mu$ m-thick sections. CSF leak did not occur. After surgery, despite the persistence of a wide remnant, the patient experienced severe hypoadrenalism. Endocrine evaluation revealed undetectable plasma ACTH and low serum cortisol levels $(5.5 \mu \mathrm{g} / \mathrm{dl}$ ) (see Table 1). For this reason, hydrocortisone replacement was started. Six months later, stereotactic radiosurgery was performed by the gamma-knife $\left(\gamma\right.$-knife) approach $\left(21 \mathrm{~Gy}\right.$, in a single radiation dose) given tumor size increase $\left(7.2 \mathrm{~cm}^{3}\right)$. This treatment induced mild tumor shrinkage, but after 2 years, MRI demonstrated tumor regrowth $\left(27.0 \mathrm{~cm}^{3}\right)$, which spread into the left cavernous sinus and extended to the suprasellar and omolateral parasellar region with encasement of left internal carotid artery. Moreover, the patient complained of severe, subcontinuous headaches and dramatic decrease of visual acuity in the left eye. Thereafter, left cranial orbitozygomatic craniotomy with extensive resection of the pituitary tumor was performed. Pathology showed increased mitotic activity, bone invasion, and prominent cytological atypia. Immunohistochemistry was focally and weakly positive for ACTH. A nonspecific immunopositivity for growth hormone $(\mathrm{GH})$ was also found. Moreover, Ki-67 index increased to 4\%, while p53 was negative. However, soon after surgery, a huge tumor remnant was still evident and progressive tumor size increase was demonstrated by MRI after 1 year. For this reason, the patient underwent further subtotal resection of the tumor remnant by left craniotomy. Immunohistochemistry was focally positive only for ACTH and demonstrated that Ki-67 index was increased dramatically (18\%). Six months after, in December 2008, the pituitary tumor continued to grow $\left(31.1 \mathrm{~cm}^{3}\right.$ ) and an asymptomatic intradural lesion was detected by MRI (Fig. 1A-C). Histological examination of this mass was proposed, but the patient, informed about the risk of a surgical approach, did not consent to the biopsy. However, its imaging characteristics were consistent with a metastasis, as demonstrated by high-dose contrast MRI. Therefore, in February 2009, following the 
TABLE 1

Endocrine Evaluation at Presentation and after First Surgery

\section{Basal and Dynamic Evaluation of the Hypothalamic-Pituitary-Adrenal Axis}

Morning ACTH (pg/ml)

Morning cortisol $(\mu \mathrm{g} / \mathrm{dl})$

Urinary free cortisol $(\mu \mathrm{g} / 24 \mathrm{~h})$

ACTH after high-dose dexamethasone $e^{\S}$

Cortisol after high-dose dexamethasone ${ }^{\S}$

$\mathrm{CRH}$ (i.v. $1 \mu \mathrm{g} / \mathrm{kg}$ ) stimulated ACTH (pg/ml)

$\mathrm{CRH}$ (i.v. $1 \mu \mathrm{g} / \mathrm{kg}$ ) stimulated cortisol $(\mu \mathrm{g} / \mathrm{ml})$

DDAVP* (i.v. $10 \mu \mathrm{g}$ ) stimulated ACTH

$(\mathrm{pg} / \mathrm{ml})$

DDAVP* stimulated cortisol $(\mu \mathrm{g} / \mathrm{ml})$

\section{At Presentation After Surgery}

93.0 (normal range 5.0-50.0)

44.3 (normal range 5.0-25.0)

367.6 (normal range 5.0-72.0)

69.0

27.8

$118($ peak $=143)$
$41($ peak $=45.2)$
$82($ peak $=378)$

$35.7($ peak $=63.4)$
Undetectable

5.5

14.6 (peak 17.9)

5.5 (peak 6.7)

$\S$ Oral dexamethasone suppression test (8 $\mathrm{mg}$ daily for 2 days, consecutively).

* Desmopressin acetate.
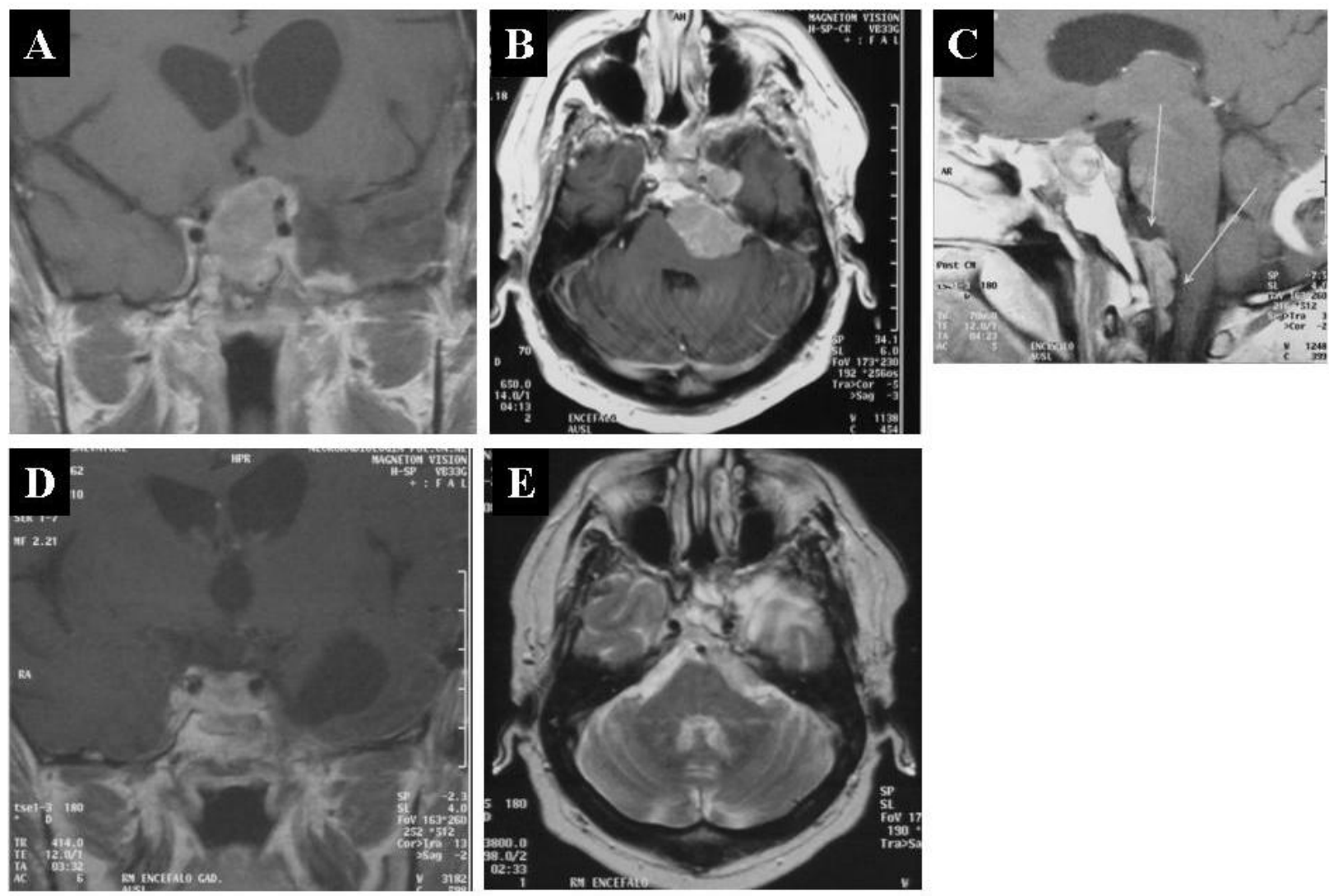

FIGURE 1. MRI evaluation before (A-C) and after (D,E) TMZ treatment. Before TMZ administration, tumor volume, investigated by sagittal, coronal (A), and axial (B) fast spin-echo (FSE) T1-weighted imaging after gadolinium-diethylenetriamine penta-acetate (Gd-DTPA) administration, was $31.1 \mathrm{~cm}^{3}$. Sagittal (C) FSE T1-weighted imaging after Gd-DTPA administration demonstrated the presence of an intradural metastasis at the foramen magnum. After four TMZ cycles, tumor volume, investigated by sagittal and coronal (D) FSE T1-weighted imaging and by axial (E) FSE T2-weighted imaging after Gd-DTPA administration, was $2.8 \mathrm{~cm}^{3}$. 
demonstration of low MGMT expression ( $<5 \%$ nuclear staining) in specimens recovered from the second surgery, TMZ was administered orally at a daily dose of $200 \mathrm{mg} / \mathrm{m}^{2}$ of body surface, for 5 days. This treatment was well tolerated except for a transient thrombocytopenia (grade $4 \mathrm{WHO}$ ) that required platelet transfusion. Seven weeks after the first cycle, TMZ was administered again at a lower daily dose (150 $\mathrm{mg} / \mathrm{m}^{2}$ ) for 5 days. Afterwards, MRI demonstrated dramatic tumor size shrinkage $\left(5.2 \mathrm{~cm}^{3}\right)$, without changes of the intradural metastasis, and the patient experienced a decided lessening of headaches. Thus, a further two TMZ cycles, at a daily dose of $150 \mathrm{mg} / \mathrm{m}^{2}$ for 5 days, were repeated every 4 weeks. The MRI performed 6 months after the end of TMZ treatment showed a further decrease of tumor size (2.8 $\mathrm{cm}^{3}$ ) and a slight reduction of the intradural metastasis (Fig. 1D,E). Clinical conditions improved progressively and, after 17 months from the beginning of TMZ administration, the patient is still alive. At present, the hypoadrenalism did not recover, while the remaining pituitary function did not change compared with the evaluation performed before TMZ treatment (see Table 2).

\section{TABLE 2}

Endocrine Evaluation Before and After TMZ Treatment

\begin{tabular}{lcc}
\hline & Before TMZ & After TMZ \\
\hline Follicle-stimulating hormone (FSH) & $3.87 \mathrm{U} / \mathrm{L}$ (normal range 0.7-11.1) & 3.7 \\
Luteinizing hormone (LH) & $4.67 \mathrm{U} / \mathrm{L}$ (normal range 0.8-7.6) & 3.8 \\
Total testosterone & $512 \mathrm{ng} / \mathrm{dl}$ (normal range 280-800) & 467 \\
Prolactin (PRL) & $260.6 \mathrm{U} / \mathrm{L}$ (normal range 86-324) & 200.4 \\
Thyroid-stimulating hormone (TSH) & $1.8 \mathrm{mU} / \mathrm{L}$ (normal range 0.27-4.2) & 2.0 \\
Free thyroxine (FT4) & $15.5 \mathrm{pmol} /$ (normal range 12-22) & 14.9 \\
Growth hormone (GH) & $0.7 \mathrm{ng} / \mathrm{ml}$ (normal range 0.2-2.0) & 0.8 \\
Insulin-like growth factor 1 (IGF-1) & $201 \mathrm{ng} / \mathrm{ml}$ (normal range 101-267) & 195 \\
Urinary free cortisol (UFC) & $37.5 \mathrm{\mu g} / 24 \mathrm{~h}$ (normal range 5.0-72.0) & $69.1^{\S}$ \\
\hline § Dosage of hydrocortisone replacement therapy was decreased after the last cycle of \\
$\quad$ TMZ.
\end{tabular}

\section{DISCUSSION}

Pituitary carcinomas are extremely rare[1,2,3] and are characterized by invasion of adjacent structures, rapid proliferation, and/or presence of distant metastases to intra- or extracranial sites[4,9]. In many cases, they are the result of the progressive transformation of an apparently benign, invasive macroadenoma. During malignant transformation, changes in hormone secretion have been reported in some cases, probably because these tumors were polyclonal, and able to express different morphology and biological activity during growth $[4,7,16]$. The demonstration of a different genetic pattern in the specimens collected when the patient in question was reoperated several times might support this hypothesis[14,17]. ACTHsecreting macroadenomas with low sensitivity to corticotropin-releasing hormone (CRH) or high-dose dexamethasone, or with low hormone secretion rate, so-called silent corticotropinomas, are at increased risk for invasiveness or transformation into carcinomas[18]. Conventionally, an invasive pituitary macroadenoma is considered carcinoma only when distant metastases occur[4]. More frequently, they are intracranial or spinal, and cause neurological symptoms[4]. Intra-abdominal or lung metastases have also been reported $[2,4,19]$. Owing to the low incidence of pituitary carcinomas, there is poor experience regarding treatment. Surgery, radiotherapy, and medical therapy with dopamine agonists, somatostatin analogs, tamoxifen, cyproheptadine, OP'DDD (mitotane), or systemic chemotherapy have been proposed in many cases, but effects are inconstant or palliative[4,10,20,21,22,23,24] and a prolongation of patients' 
long-term survival was not reported[20,25]. On the contrary, the surgical excision of metastases seemed to improve the chances of survival in some cases[26]. Recently, TMZ has been introduced in the management of malignant primary neoplasms and metastases of the CNS[27,28,29]. This drug, specific for the treatment of brain tumors due to its ability to cross the blood brain barrier and a good liposolubility in brain tissue, has also been proposed for pituitary carcinomas and aggressive pituitary adenomas resistant to conventional management[11,12]. Until now, TMZ administration has been able to reduce tumor size and improve clinical conditions in a patient with LH-secreting pituitary carcinoma, in four patients with PRL-secreting carcinoma, in a patient with mixed GH- and PRL-secreting carcinoma, and in three patients with ACTH-secreting pituitary carcinoma[11,12,15,30,31,32,33,34,35]. Fadul et al.[11] also reported a patient with PRL-secreting carcinoma in whom TMZ induced improvement of clinical condition, dramatic PRL level decrease, and tumor volume reduction at the beginning of treatment. Nevertheless, discontinuation of TMZ was followed, 15 months after, by increased PRL levels and metastasis recurrence. More recently, a significant tumor shrinkage with a decreased hormone secretion was reported by Raverot et al. in two out of five patients with pituitary carcinoma (one with ACTH- and another with PRL-secreting carcinoma) included in a French multicenter study[13]. In these patients, the efficacy of TMZ was demonstrated after only three cycles of treatment. Other studies reported several cases with invasive secreting or nonfunctioning pituitary adenomas effectively treated with this drug[12,13,36,37,38,39,40]. TMZ promotes apoptosis of target cells, causing alkylation and methylation of guanine residues in DNA, and induces massive cell shrinkage and necrosis. Its effectiveness is related to the tumor down-expression of MGMT, an enzyme able to repair this type of DNA damage[12,15]. Accordingly, high MGMT expression was reported in a nonfunctioning pituitary adenoma not responding to TMZ[41] and in a case of aggressive ACTH-secreting pituitary adenoma that transformed into a carcinoma 4 months after TMZ withdrawal[34]. On the contrary, MGMT expression was high in an ACTH-secreting carcinoma responding, and low in a PRL-secreting carcinoma and in an aggressive ACTH-secreting adenoma not responding, to TMZ[13]. Moreover, a marked heterogeneity in MGMT expression was found in many cases, with a predominant expression both in single regions and in the periphery of the tumor[40]. For this reason, MGMT status should be considered a poor predictor of treatment outcome and it should not be used for the selection of patients candidate to TMZ therapy.

In our patient, the treatment induced a dramatic lessening of headaches. After four TMZ cycles, pituitary tumor volume was reduced by more than $90 \%$ and a stabilization of the metastasis volume was documented. The drug was well tolerated and transient thrombocytopenia, managed by platelet transfusion, was the only side effect that occurred after the first cycle of treatment.

In conclusion, TMZ can be considered an effective and safe approach to aggressive pituitary tumors. Moreover, a short trial with TMZ could be useful to identify potential responder patients in comparison with the MGMT expression.

\section{REFERENCES}

1. Pernicone, P.J. and Scheithauer, B.W. (2001) Invasive pituitary adenoma and pituitary carcinoma. In Diagnosis and Management of Pituitary Tumors. Thapar, K., Kovacs, K., Scheithauer, B.W., et al., Eds. Humana Press, Totowa, NJ. pp. 369-386.

2. Pernicone, P.J., Scheithauer, B.W., Sebo, T.J., et al. (1997) Pituitary carcinoma: a clinicopathologic study of 15 cases. Cancer 79, 804-812.

3. Pichard, C., Gerber, S., Laloi, M., et al. (2002) Pituitary carcinoma: report of an exceptional case and review of the literature. J. Endocrinol. Invest. 25, 65-72.

4. Ragel, B.T. and Couldwell, W.T. (2004) Pituitary carcinoma: a review of the literature. Neurosurg. Focus 16, 1-9.

5. Scheithauer, B.W., Randall, R.V., Laws, E.R., Jr., Kovacs, K.T., Horvath, E., and Whitaker, M.D. (1985) Prolactin cell carcinoma of the pituitary. Clinicopathologic, immunohistochemical, and ultrastructural study of a case with cranial and extracranial metastases. Cancer 55, 598-604.

6. Scheithauer, B.W., Kurtkaya-Yapicier, O., Kovacs, K.T., Young, W.F., Jr., and Lloyd, R.V. (2005) Pituitary carcinoma: a clinicopathological review. Neurosurgery 56, 1066-1074.

7. Farrell, W.E., Coll, A.P., Clayton, R.N., and Harris, P.E. (2003) Corticotroph carcinoma presenting as a silent corticotroph adenoma. Pituitary 6, 41-47. 
8. Lopes, M.B., Scheithauer, B.W., and Schiff, D. (2005) Pituitary carcinoma: diagnosis and treatment. Endocrine 28, $115-121$.

9. Kovacs, K., Scheithauer, B.W., Horvath, E., and Lloyd, R.V. (1996) The World Health Organization classification of adenohypophysial neoplasms. A proposed five-tier scheme. Cancer 78, 502-510.

10. Kaltsas, G.A., Nomikos, P., Kontogeorgos, G., Buchfelder, M., and Grossman, A.B. (2005) Clinical review: diagnosis and management of pituitary carcinomas. J. Clin. Endocrinol. Metab. 90, 3089-3099.

11. Fadul, C.E., Kominsky, A.L., Meyer, L.P., et al. (2006) Long-term response of pituitary carcinoma to temozolamide. Report of two cases. J. Neurosurg. 105, 621-626.

12. Hagen, C., Schroder, H.D., Hansen, S., Hagen, C., and Andersen, M. (2009) Temozolamide treatment of a pituitary carcinoma and two pituitary macroadenomas resistant to conventional therapy. Eur. J. Endocrinol. 161, 631-637.

13. Raverot, G., Sturm, N., de Fraipont, F., et al. (2010) Temozolomide treatment in aggressive pituitary tumors and pituitary carcinomas: a French multicenter experience. J. Clin. Endocrinol. Metab. 95, 4592-4599.

14. Syro, L.V., Ortiz, L.D., Scheithauer, B.W., et al. (2010) Treatment of pituitary neoplasms with temozolomide: a review. Cancer [Epub ahead of print]

15. Takeshita, A., Inoshita, N., Taguchi, M., et al. (2009) High incidence of low $\mathrm{O}^{6}$-methylguanine DNA methyltransferase expression in invasive macroadenomas of Cushing's disease. Eur. J. Endocrinol. 161, 553-559.

16. Zahedi, A., Booth, G.L., Smyth, H.S., et al. (2001) Distinct clonal composition of primary and metastatic adrenocorticotrophic hormone-producing pituitary carcinoma. Clin. Endocrinol. 55, 549-556.

17. Clayton, R.N., Pfeifer, M., Atkinson, A.B., et al. (2000) Different patterns of allelic loss (loss of heterozygosity) in recurrent human pituitary tumors provide evidence for multiclonal origins. Clin. Cancer Res. 6, 3973-3982.

18. Roncaroli, F., Scheithauer, B.W., Young, W.F., et al. (2003) Silent corticotroph carcinoma of the adenohypophysis: a report of five cases. Am. J. Surg. Pathol. 27, 477-486.

19. Atienza, D.M., Vigersky, R.J., Lack, E.E., et al. (1991) Prolactin-producing pituitary carcinoma with pulmonary metastases. Cancer 68, 1605-1610.

20. Landman, R.E., Horwith, M., Peterson, R.E., Khandji, A.G., and Wardlaw, S.L. (2002) Long-term survival with ACTH-secreting carcinoma of the pituitary: a case report and review of the literature. J. Clin. Endocrinol. Metab. 87, 3084-3089.

21. Levesque, H., Freger, P., Gancel, A., Tayot, J., and Courtois, H. (1991) Primary carcinoma of the pituitary gland with Cushing's syndrome and metastases. Apropos of a case with review of the literature. Rev. Med. Interne 12, $209-212$. Lormeau, B., Miossec, P., Sibony, M., Valensi, P., and Attali, J.R. (1997) Adrenocorticotropin-producing pituitary carcinoma with liver metastasis. J. Endocrinol. Invest. 20, 230-236.

Masuda, T., Akasaka, Y., Ishikawa, Y., et al. (1999) An ACTH-producing pituitary carcinoma developing Cushing's disease. Pathol. Res. Pract. 195, 183-187.

24. Kaltsas, G.A. and Mukherjee, J.J. (1998) The role of cytotoxic chemotherapy in the management of aggressive and malignant pituitary tumors. J. Clin. Endocrinol. Metab. 83, 4233-4238.

25. Kaltsas, G.A. and Grossman, A.B. (1998) Malignant pituitary tumours. Pituitary 1, 69-81.

26. van der Klaauw, A.A., Kienitz, T., Strasburger, C.J., Smit, J.W., and Romijn, J.A. (2009) Malignant pituitary corticotroph adenomas: report of two cases and a comprehensive review of the literature. Pituitary 12, 57-69.

27. Glantz, M., Chamberlain, M., Liu, Q., Litofsky, N.S., and Recht, L.D. (2003) Temozolomide as an alternative to irradiation for elderly patients with newly diagnosed malignant gliomas. Cancer 97, 2262-2266.

28. Stupp, R., Dietrich, P.Y., Ostermann Kraljevic, S., et al. (2002) Promising survival for patients with newly diagnosed glioblastoma multiforme treated with concomitant radiation plus temozolomide followed by adjuvant temozolomide. J. Clin. Oncol. 20, 1375-1382.

29. Stupp, R. and Newlands, E. (2001) New approaches for temozolomide therapy: use in newly diagnosed glioma. Semin. Oncol. 28, 19-23.

30. Zhu, Y., Shahinian, H., Hakimian, B., Bonert, V., Lim, S., and Heaney, A. (2004). Temodar: novel treatment for pituitary carcinoma. US Endocr. Soc. 138, 43-45.

31. Lim, S., Shahinian, H., Maya, M.M., Yong, W., and Heaney, A.P. (2006) Temozolomide: a novel treatment for pituitary carcinoma. Lancet 7, 518-520.

32. McCormack, A.I., McDonald, K.L., Gill, A.J., et al. (2009) Low $\mathrm{O}^{6}$-methylguanine-DNA methyltransferase (MGMT) expression and response to temozolomide in aggressive pituitary tumours. Clin. Endocrinol. 71, 226-233.

33. Byrne, S., Karapetis, C., and Vrodos, N. (2009) A novel use of temozolomide in a patient with malignant prolactinoma. J. Clin. Neurosci. 16, 1694-1696.

34. Mohammed, S., Kovacs, K., Mason, W., Smyth, H., and Cusimano, M.D. (2009) Use of temozolamide in aggressive pituitary tumors: case report. Neurosurgery 64, E773-E774.

35. Thearle, M., Freda, P., Bruce, J., Isaacson, S., Lee, Y., and Fine, R. (2009) Temozolomide (Temodar®) and capecitabine $\left(\right.$ Xeloda $\left.{ }^{\circledR}\right)$ treatment of an aggressive corticotroph pituitary tumor. Pituitary [Epub ahead of print]

36. Neff, L.M., Weil, M., Cole, A., et al. (2007) Temozolomide in the treatment of an invasive prolactinoma resistant to dopamine agonists. Pituitary 10, 81-86.

37. Kovacs, K., Horvath, E., Syro, L.V., et al. (2007) Temozolomide therapy in a man with an aggressive prolactinsecreting pituitary neoplasm: morphological findings. Hum. Pathol. 38, 185-189. 
38. Syro, L.V., Uribe, H., Penagos, L.C., et al. (2006) Antitumour effects of temozolomide in a man with a large, invasive prolactin-producing pituitary neoplasm. Clin. Endocrinol. 65, 552-553.

39. Moyes, V.J., Alusi, G., Sabin, H.I., et al. (2009) Treatment of Nelson's syndrome with temozolomide. Eur. J. Endocrinol. 160, 115-119.

40. Bush, Z.M., Longtine, J.A., Cunningham, T., et al. (2010) Temozolomide treatment for aggressive pituitary tumors: correlation of clinical outcome with O6-methylguanine methyltransferase (MGMT) promoter methylation and expression. J. Clin. Endocrinol. Metab. [Epub ahead of print]

41. Kovacs, K., Scheithauer, B.W., Lombardero, M., et al. (2008) MGMT immunoexpression predicts responsiveness of pituitary tumors to temozolomide therapy. Acta Neuropathol. 115, 261-262.

\section{This article should be cited as follows:}

Curtò, L., Torre, M.L., Ferraù, F., Pitini, V., Altavilla, G., Granata, F., Longo, M., Hofland, L.J., Trimarchi, F., and Cannavò, S. (2010) Temozolomide-induced shrinkage of a pituitary carcinoma causing Cushing's disease — report of a case and literature review. TheScientificWorldJOURNAL 10, 2132-2138. DOI 10.1100/tsw.2010.210. 


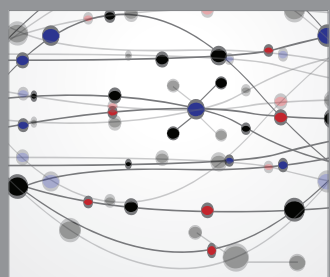

The Scientific World Journal
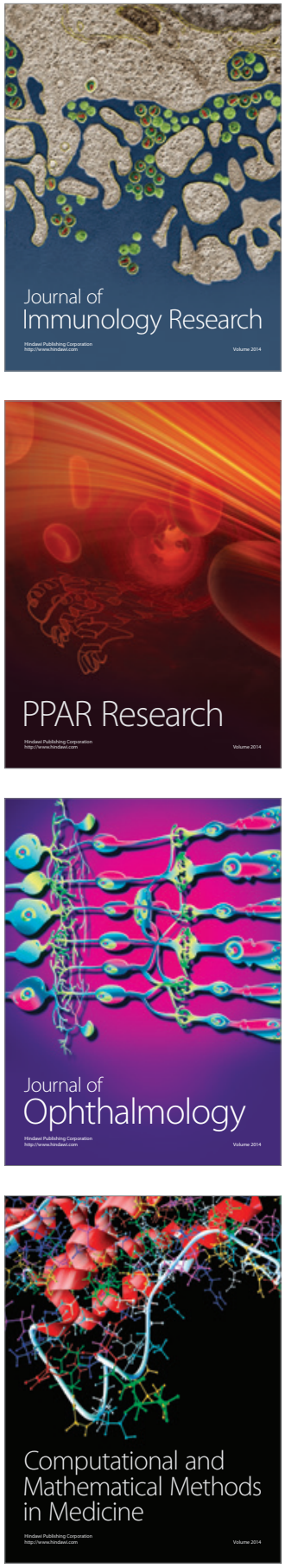

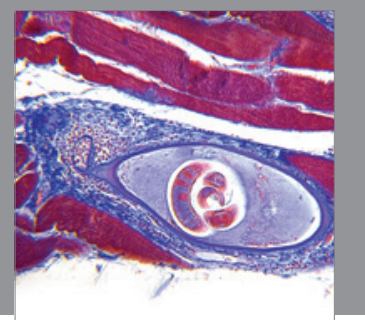

Gastroenterology

Research and Practice
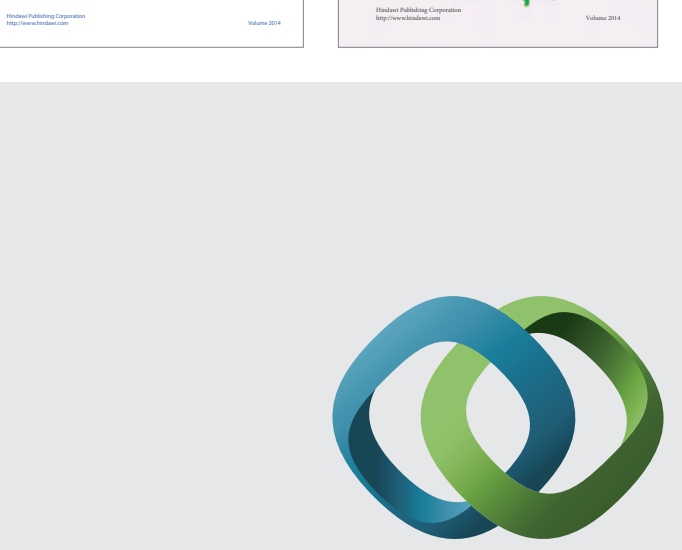

\section{Hindawi}

Submit your manuscripts at

http://www.hindawi.com
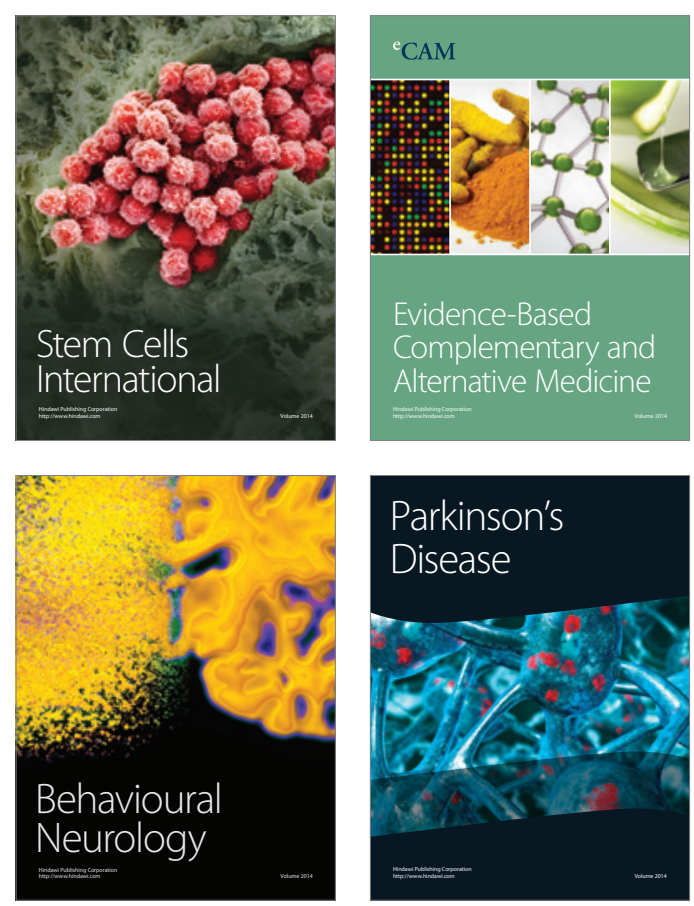

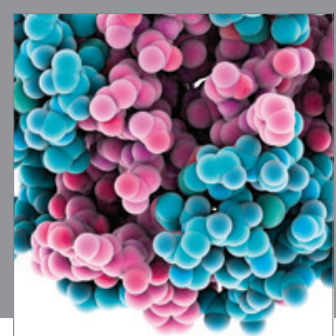

Journal of
Diabetes Research

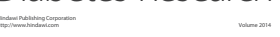

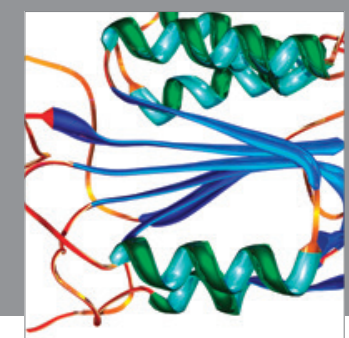

Disease Markers
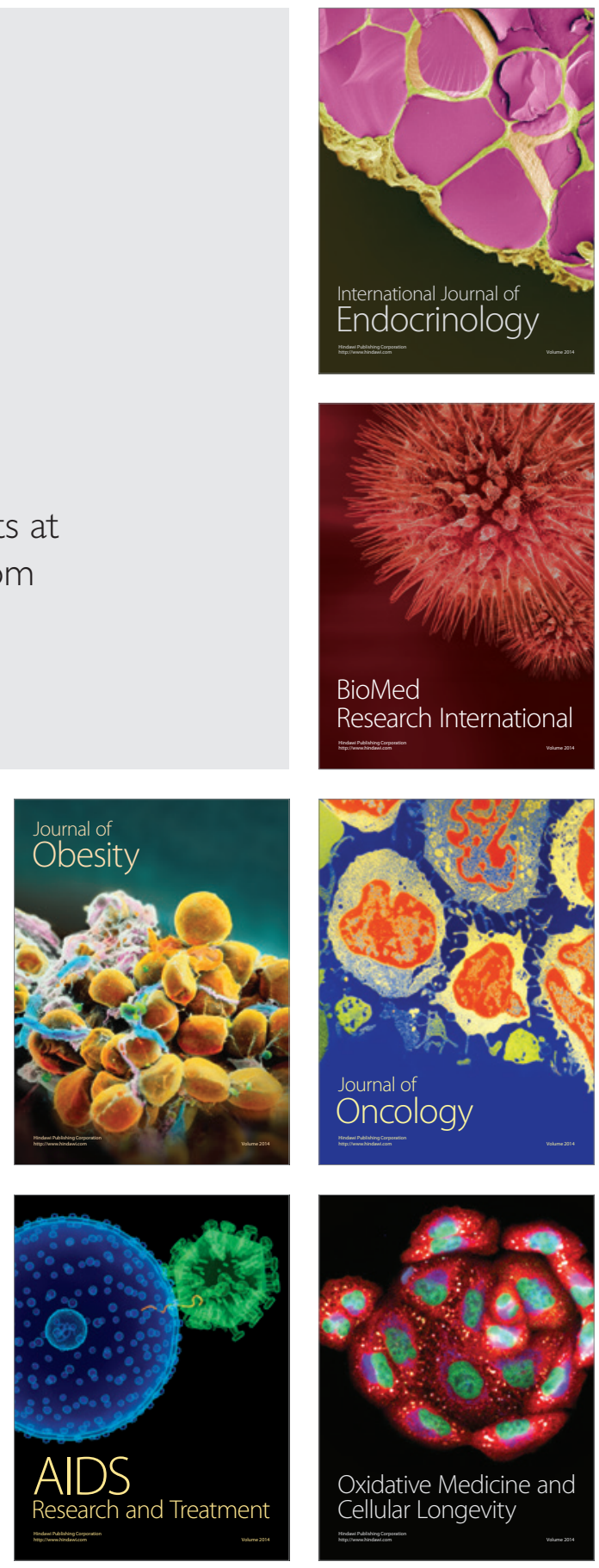